\title{
Environmental, Social, and Governance (ESG) Investing: Risk and Return Analysis of Egyptian Sustainable Equity Index
}

\author{
Mahmoud Otaify \\ Faculty of Business Administration, Economics and Political Science, \\ The British University in Egypt. \\ Mahmoud.otaify@bue.edu.eg
}

\begin{abstract}
The present paper aims to compare risk and return characteristics of ESG index with those of conventional benchmark market index: EGX30 for a period from June 2007 to September 2020. We apply GARCH models not only to examine the volatility features of each index but also to investigate effect of exogenous shocks to stock market including global financial crisis in 2008 (GFC), political uncertainty after Egyptian revolution in 2011 (ER2011) and most recently potential effects of covid-19 pandemic. The results reveal that the daily compounded returns of the ESG Index are not statistically different from those of the EGX30 index, however, annualized returns of the ESG Index have been better than the returns of the EGX30 index. Interestingly, the annualized returns of ESG index outperform those of EGX30 index during the exogenous shock periods. Conversely, the ESG returns tend to underperform EGX30 returns during normal time periods, except the pre-Egyptian revolution period. We find that volatility of ESG index returns is more persistent than that of benchmark index, but the returns of benchmark index has larger leverage effect than those of ESG index. The findings have three important practical implications. Firstly, portfolio managers could follow ESG investing to diversify their portfolios and
\end{abstract}


maximize returns. Secondly, firms listed in Egyptian exchange should adopt more environmental, social, governance issues in their policies to maximize firm value. Thirdly, asset pricing models could be extended to include ESG premium factor in explaining cross-sectional returns in the Egyptian exchange.

Key word: S\&P/EGX ESG index, Sustainable Investing, Socially Responsible Investing, Precautionary Procedures, COVID-19

\section{Introduction}

Environmental, Social and Governance (ESG) issues are described in different labels including socially responsible investing (SRI), responsible investing, ethical, sustainable investing. Traditional SRI implies avoiding morally questionable business while sustainable investing seeks to define investment risks and opportunities in the context of ESG analysis. Investors consider ESG issues as non-financial factors in their investment analysis process to define risk and growth opportunities while other investors consider these issues as moral values, however, both categories commonly focus on ESG issues (CFAInstitute, 2015). In general, SRI is an investment strategy involves selecting stocks according to their environmental, social, and ethical screens. This investment strategy gets its acceptance worldwide with the introduction of the Principles for Responsible Investment (PRI) in 2006 (Rehman, Zhang, Uppal, Cullinan, \& Naseem, 2016). ${ }^{1}$ Following socially responsible trading strategy - buying high ranked stocks and sell low ranked stocks - resultes in abnormal return of 8.7\%, annually (Kempf \& Osthoff, 2007).

The United Nations Secretary-General launched its Sustainable Stock Exchanges (SSE) initiative in 2009 to improve exchange-listed firms' transparency and commitment to environmental, social, and corporate governance (ESG) issues. The Egyptian exchange (EGX) was one of the four

\footnotetext{
${ }^{1}$ PRI seeks to consider ESG issues in making investment decisions.
} 
pioneer exchanges participating in this initiative. In 2010, EGX introduced the sustainability index (S\&P/EGX ESG) which is the first index in Middle East and North Africa (MENA) region and second worldwide. The Environment, Social and Governance (ESG) index of Egypt is developed by the Egyptian Institute of Directors (EIOD) and Standard \& Poor's. Under guidance of S\&P, EIoD implements ESG research to give appropriate scores for listed firms while Egyptian exchange (EGX) ensures consistency of historical data. S\&P/EGX ESG index aims at raising firms' profiles with respect to their practices of environmental, social and corporate governance responsibility as compared to their peer companies in the same industry or market. Typically, the Egyptian Exchange conducts annual screening for Egyptian Companies which involves three types of scoring: quantitative score - values are assigned for corporate governance, environmental \&social governance practices; qualitative score - a scale of 1 to 5 is assigned for each company according to its available information, news stories, web sites and corporate social responsibility CSR filings; and composite score - sum of the qualitative score and the quantitative score. A pool of 100 companies with the highest EGS composite scores are grouped to subsequently select the top 30 stocks as constituents of the index. ${ }^{2}$

A large body of literature has been attempted to examine risk and return characteristics of socially responsible investing against conventional or traditional indexes either in developed or developing countries. Arguably, the results are mixed and can be divided into three groups: the first group of studies supports "no difference" hypothesis, assuming that there is no significant difference in risk-adjusted return measures between ESG index and its benchmark market index (e.g., Schroder, 2007; Cortez, Silva and Areal, 2011; Managia, Okimoto, \& Matsuda, 2012; Rehman, et. al., 2016). The second group of research supposes that ESG indexes underperform the benchmark traditional indexes (e.g., Ortas, Moneva and Salvador, 2010). The third group of studies find that ESG indexes outperform the

\footnotetext{
${ }^{2}$ For more information about index methodology, you can visit the index page on official web site of Egyptian exchange, https://www.egx.com.eg/en/indexrulesmethodologys-p-egx.aspx?nav=7.
} 
conventional indexes (e.g., Kempf \& Osthoff, 2007; Sudha, 2014; Tripathi and Kaur, 2020).

The development of S\&P/EGX ESG in Egypt index is not only an effective way to show how investors react to ESG practices of listed firms, but it also has attracted

interest of academic finance. Aboud and Diab (2018) find that firms listed in the Egyptian sustainability index have higher firm value (measured by Tobin's q) and this relation tends to increase as the rank of the firm in the index raises. Thus, firms should enhance their social and governance practices and thereafter improve their disclosure and reporting standards. Abo-Elala (2018) examine impact of listing in ESG index on the accounting conservatism in the financial reports of the companies. He finds that firms listed on the ESG index are conservative in their financial reporting. ElMahdy (2019) investingates effect of firms' corporate governance mechanisms (board size, board composition, CEO duality and firms' weight in S\&P EGX/ESG index) on firms' financing decisions (measured by leverage ratio). Results reveal that board size and firm's weight in S\&P EGX/ESG index are significantly, negatively affect firms' debt ratio. Aboud and Diab (2019) investigate impact of ESG ratings of most active 100 listed firms in the Egyptian exchange on their financial and market performance taking into consideration the potential effect of Egyptian revolution in 2011. They find that highly ESG rated firms have better performance especially during the post revoluion period. To our best knowledge, there is no study explicitly examine risk and return performance of ESG Egypt index in comparison with benchmark market index.

This paper contributes to the literature in two ways. Firstly, it covers the gap in literature regarding risk-return performance of ESG index in Egypt compared with the broad market index, EGX30 as benchmark. Secondly, it examines risk and return characteristics during different periods including global financial crisis, political uncertainty following Egyptian revolution in 2011 and the current covid-19 pandemic in 2020. 
The remainder of the paper is organized as follows. Section 2 presents literature review while section 3 shows data and methodology applied and section 4 displays results that is discussed in section 5. At the end, section 6 presents conclusion and recommendations.

\section{Literature Review}

In this section, we review previous studies that examined the risk and return profiles of SRI indexes or funds compared with those of conventional benchmarks market indexes or funds to show methods used and major results.

Schröder (2004) uses different measures of return performance (mean return, sharp ratio, Jensen's Alpha) to examines the performance of 16 German and Swiss funds and 30 U.S. SRI funds. The author documents similar risk-adjusted performance for socially screened assets and conventional assets. Schröder (2007) applies sharp ratio, Jensen's Alpha and beta coefficient to investigate the risk-return characteristics of 29 international SRI equity indices compared to conventional benchmark indices. Results indicate that risk-adjusted returns of SRI indexes do not differ significantly from those of conventional benchmarks. However, returns of SRI indices tend to be more volatile than those of conventional indices. Consistently, Cortez, Silva and Areal (2011) compare performance of US and European global socially responsible SRI funds with conventional funds. They find that there are no significant differences for most European SRI funds while US and Austrian SRI funds underperform their conventional funds. Managia, Okimoto, \& Matsuda (2012) use Markov Switching model to compare return and volatility of SRI indexes with those of conventional stock indexes in the US, the UK and Japan. They find no significant difference in either region, but they document strong association between the two indexes. Rehman, et. al. (2016) use a data of eight Asian countries to examine risk and return characteristics of ESG indexes against conventional indexes. They found no significant differences in risk-adjusted returns 
between ESG indexes and the conventional indexes. The similarlity in performance between ESG indexes and conventional indexes in suggests that investors could follow SRI strategy without considerable difference in their portfolio performance from conventional investing.

Some studies find strong evidence on underperformance of SRI indices against the benchmark indices. For example, Ortas, Moneva and Salvador (2010) examine both risk-adjuted returns and conditional volatility of SRI index and market index in Spanish market. They find that riskadjusted returns (measured by Jensen's Alpha) of SRI underperform its benchmark index. Results of GARCH model show that SRI index is less volatile that the benchmark market index. They find that SRI equity index is less sensitive to the negative effects of global financial crisis in mid 2008.

In contrast, Curto and Vital (2014) use daily returns of 10 sustainable and 4 traditional stock indexes to investigate effect of using sustainability criteria in portfolio selection on returns. They find that returns of sustainable indexes outperform those of traditional indexes. Consistently, Sudha (2014) uses sharp and Trenyor ratios to compare performance of sustainability index of India with two benchmark broad markets. Moreover, the author attempts to model their volatility prospects using generalized autoregressive conditional heteroscedasticity $(\mathrm{GARCH})$ models. The annualized returns of the ESG index are greater than those of the two benchmark indexes. Volatility clustering is present in all the three indexes series. Interestingly, the ESG index is less volatile than market index.

Most recently studies, for example, Tripathi and Kaur (2020) use various risk-adjusted measures and conditional volatility $(\mathrm{GARCH})$ models to analyze performance of socially responsible indices of BRICS $^{3}$ nations in comparison with their conventional market indices over 12 years. They provide implications for different sectors in society: BRICS organization, investors, Companies and regulatory bodies and Asset Managers. In general,

${ }^{3}$ BRICS nations include Brazil, Russia, India, China, and South Africa 
they advise investors and asset managers to include of socially responsible stocks in their portfolios and advise companies and regulatory issues to unify their efforts to enhance corporate reporting and disclosures. Arefeen and Shimada (2020) apply event study with market model using different econometric models to examine performance of both socially responsible and conventional funds in Japan during two shocks: the US election and Brexit in 2016. They find that SRI funds are more sensitive to uncertainty associated with US election while conventional funds are more sensitive during the Brexit referendum.

Many authors use SRI mutual funds in their analysis of risk and return characteristics and others use SRI indices. The current paper uses SRI index to avoid managerial issues related to mutual funds including transaction costs of funds, the timing activities and the managers skills of the fund management (Schroder, 2007). This paper seeks to achieve three objectives; (1) compare risk-adjusted return measures for ESG and EGX30 indexes during different periods., (2) examine volatility in returns of ESG index and EGX30 index using GARCH models, (3) capture potential effects of exogenous shocks on conditional volatility of indices.

\section{Data and Methodology}

\subsection{Data}

We use daily and monthly data for EGX30 index as well as for the S\&P/EGX ESG index over the period $28^{\text {th }}$ of June $2007-23^{\text {rd }}$ of September 2020. We extract data for the indexes of interest from the Egyptian Exchange web site. In the mid-September 2008, foreign investors in the Egyptian exchange began liquidating their portfolios to cover losses in their home markets, resulting in 52\% drop in the EGX30 index (EGX annual Report, 2008). At the end of September 2009, EGX30 index recorded its highest level (since Sep. 2008) at 7000 points (EGX Annual Report, 2009). Thus, we add dummy variable to capture potential effect of the global financial crisis (GFC) which takes one in the period (Sep. 2008 - Aug. 2009) and zero otherwise.

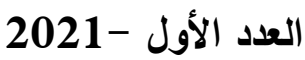

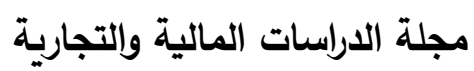


Due to the Egyptian revolution on $25^{\text {th }}$ of January 2011, the EGX 30 index sharply dropped by $30 \%$ and $16 \%$ on the 26th and 27th of January 2011, respectively. As a result of the security absence, banks are closed and trading on EGX is suspended for almost two months. To protect investors' rights and limit potential excessive volatility, EGX adopts precautionary procedures to resume trading on the 23rd of March 2011. On $21^{\text {st }}$ July 2014, EGX removed the precautionary procedures. Similarly, we add a dummy variable to reflect the period of the political uncertainty post the Egyptian revolution which takes one during the period: 25 January 2011 - 21 July 2014 and zero otherwise.

In March 2020, the Egyptian government adopts protective procedures to manage diffusion of corona virus (Covid-19), therefore we develop a third dummy variable which takes one for days during the period: March $2020-$ Sep. 2020 and zero otherwise to capture the potential effect of CORNONA virus on stock market.

\subsection{Risk-adjusted Return Performance}

Most of studies apply Sharpe ratios, Treynor ratio and Jensen's alpha to evaluate return performance. Previously, we should calculate continuously compounded daily returns for each index using the following equation:

$$
R_{i, t}=\ln \left(\frac{P_{i, t}}{P_{i-1, t}}\right) \times 100
$$

Where $P_{i, t}$ denotes the closing value of index $i$ on day $t . R_{i, t}$ is portfolio (index) return on day t.

Sharp (1966) ratio is the excess return of an asset over risk-free return divided by its standard deviation. Thus, this ratio is called risk-adjusted return because it computes the differential return of asset for each unit of risk. The sharp ratio takes the following form 


$$
\text { Sharp Rario }=\frac{R_{i}-R_{f}}{\sigma_{i}}
$$

Where $R_{i}$ is the return of an index, $\mathrm{i}$ (ESG or EGX30), $R_{f}$ is the risk-free rate of return and $\sigma_{i}$ is the standard deviation of index, $i$, returns. The second measure for the risk-adjusted return is Jensen's alpha which measures average risk premium for each unit of market risk. We can estimate alpha using the following equation:

$$
\alpha^{E S G}=\left(R_{t}^{E S G}-R_{f}\right)-\beta e t a^{E S G}\left(R_{t}^{E G X 30}-R_{f}\right)+\varepsilon^{E S G}
$$

Where $\alpha^{E S G}$ is the abnormal return achieved by ESG index than the EGX30 index. $\beta e t a^{E S G}$ is a beta coefficient measures risk exposure of ESG index to market benchmark index, EGX30. If $\beta^{E S G}<1$, the EGS index is less risky than benchmark market index. Importantly, this equation is a re-arrangement of the well-known model in finance, that is, Capital Asset Pricing Model (CAPM). The third measure of risk-adjusted return is Treynor ratio by which the excess return is adjusted by beta coefficient and it takes the following mathematical setting:

$$
\text { Treynor } \text { Rario }_{i}=\frac{R_{i}-R_{f}}{\text { Beta }_{i}}
$$

$B e t a_{i}$ is beta coefficient for index, $\mathrm{i}$ where beta for ESG index is estimated from equation (3) while that of market benchmark (EGX30) index equals one.

\subsection{Conditional Volatility Model}

Classical GARCH model can depict the volatility clustering - large (small) stock return tends to be followed by large (small) stock return. However, finance empirical evidence indicates the presence of asymmetric effect in financial time series - negative return shocks have greater impact on the 
conditional volatility than positive return shocks of the same magnitude. Thus, we follow Sudha (2014) and Tripathi and Kaur (2020) in using an asymmetric GARCH model known as Threshold GARCH (TGARCH) to model stock return volatility because it captures the leverage effect.

The volatility model, the AR $(1)-T G A R C H(1,1)$ takes the following empirical setting:

$$
\begin{gathered}
R_{i t}=\varphi+\theta R_{i t-1}+\varepsilon_{i t} \\
\varepsilon_{i t} \mid \Psi_{t-1} \sim N\left(0, h_{i t}\right) \\
h_{j t}=\omega+\alpha \varepsilon_{i t-1}^{2}+\eta I_{t-1} \varepsilon_{i t-1}^{2}+\beta h_{i t-1} \\
\text { If } \varepsilon_{i t-1}<0(\text { bad news }), I_{t-1}=1
\end{gathered}
$$$$
\text { If } \varepsilon_{i t-1}>0 \text { (good news), } I_{t-1}=0
$$

Equation (2) is the conditional mean equation where $R_{i t}$ is the daily rate of return for an index, $i$ where $i=E S G$ or $E G X 30$. The coefficient $\theta$ measures the first order serial correlation in the portfolio returns. $\Psi_{t-1}$ denotes an extended information set including the history of portfolio returns up to day $t-1$.

The conditional variance equation (3) indicates that the conditional variance of portfolio returns $h_{j t}$ is a function of three terms; $\varepsilon_{i t-1}^{2}$ is the ARCH term, $I_{t-1} \varepsilon_{i t-1}^{2}$ is the asymmetric effect term and $h_{i t-1}$ is the GARCH term. The Coefficient $\eta$ measures the asymmetric response of volatility to good and bad news, if $\eta$ is positive, it specifies that the asymmetric effect is present. The conditions for non-negative and non-degenerate $h_{j t}$ and covariance stationary are $\omega>0,0<\alpha<1,0 \leq \beta<1, \alpha+\eta \geq 0$ and $\alpha+\frac{\eta}{2}+\beta<1$.

Since the sample period overlaps periods of global financial crisis, the Egyptian revolution in January 2011, and corona virus, it reasonable to add dummy variables to capture the potential effects of those exogenous shocks on conditional volatility of each portfolio (index). Thus the equation of conditional volatility (3) will be modified as follow: 


$$
\begin{gathered}
h_{i t}=\omega+\alpha \varepsilon_{i t-1}^{2}+\eta I_{t-1} \varepsilon_{i t-1}^{2}+\beta h_{i t-1}+\phi_{1} D U M G F C+\phi_{2} \text { DUMpolitic } \\
+\phi_{3} D U M C O V I D 19
\end{gathered}
$$

Coefficients of the dummy variables, $\Phi_{1}, \Phi_{2}, \phi_{3}$ describe the response of portfolio return volatility to the GFC2008, the political uncertainty in Egypt following the ERJ2011, and COVID-19 virus, respectively. Each dummy variable takes one during its period of interest and zero otherwise.

\section{Results}

Table 1 shows descriptive statistics of mean returns for ESG index compared to that of EGX30 index. The mean daily return of ESG index exceeds slight that of EGX30 index and similarly standard deviation of mean return of ESG index is greater than that of EGX30 index, indicating that investing in ESG index tends to be riskier than investing in EGX30 index.

Table 1: Descriptive Statistics of Index Series Daily Returns

\begin{tabular}{ccccccccc}
\hline & Mean & Median & Standard Deviation & Kurtosis & Skewness & Min. & Max. & Obs. \\
\hline ESG-R & 0.00015 & 0.0011 & 0.018079 & 10.60627 & -1.09806 & -0.2189 & 0.1039 & 3214 \\
EGX30-R & 0.00011 & 0.0009 & 0.016341 & 8.75908 & -1.03897 & -0.1799 & 0.0731 & 3214 \\
\hline
\end{tabular}

Source: Prepared by Researcher Using Microsoft Excel Program.

\subsection{Risk-adjusted Returns of Index Series}

We conduct two-sample mean comparison to investigate whether difference of mean returns between ESG index and EGX30 index is significant. the value of t-test indicates that there is no significant difference between mean daily return of EGS index and that of EGX30 index (shown in table 2). This result is consistent with that of Sudha (2014). Table () shows annualized mean returns for each index, indicating higher difference between ESG index and EGX30 index is in favor of the ESG where it has mean return of 3.8\% p.a. compared with the EGX30 index that has a mean return of $2.7 \%$ p.a. for the entire period. On the other hand, annualized standard deviation of EGS returns (29\%) is greater than that of EGX30 index (26\%) during the entire period. 
Table 2 Two-sample mean comparison test

\begin{tabular}{|c|c|c|c|c|c|}
\hline & $\begin{array}{l}\text { ESG } \\
\text { Index }\end{array}$ & Returns and & EGX30 & $\begin{array}{l}\text { t test for } \\
\text { returns }\end{array}$ & difference of mean \\
\hline & & 0.0000435 & & & 0.101189 \\
\hline Probability & & & & 597017 & \\
\hline
\end{tabular}

Source: Prepared by Researcher Using Microsoft Excel.

We argue that difference in returns between the two indexes change across different periods. As depicted in figure (1), annualized return of ESG outperforms EGX30 indexes in four sub-periods (GFC, Pre-ER2011, Pol.Unc., COVID19) while it underperforms the market benchmark in two subperiods; Pre-GFC and Pre-COVID19. In other words, ESG index tends to underperform the market in normal sub-periods while it outperforms the market during the exogenous shocks periods. During both Global financial crisis (GFC) period and COVID19 pandemic period, the ESG index has fewer negative returns than the EGX30 index. During the political uncertainty period, annualized returns of ESG index; 12\%, significantly outperform the benchmark EGX30 index; 12\%. However, annualized standard deviations of both indexes tend to be close across different periods with a superior risk for account of the ESG index (as shown in figure 3).

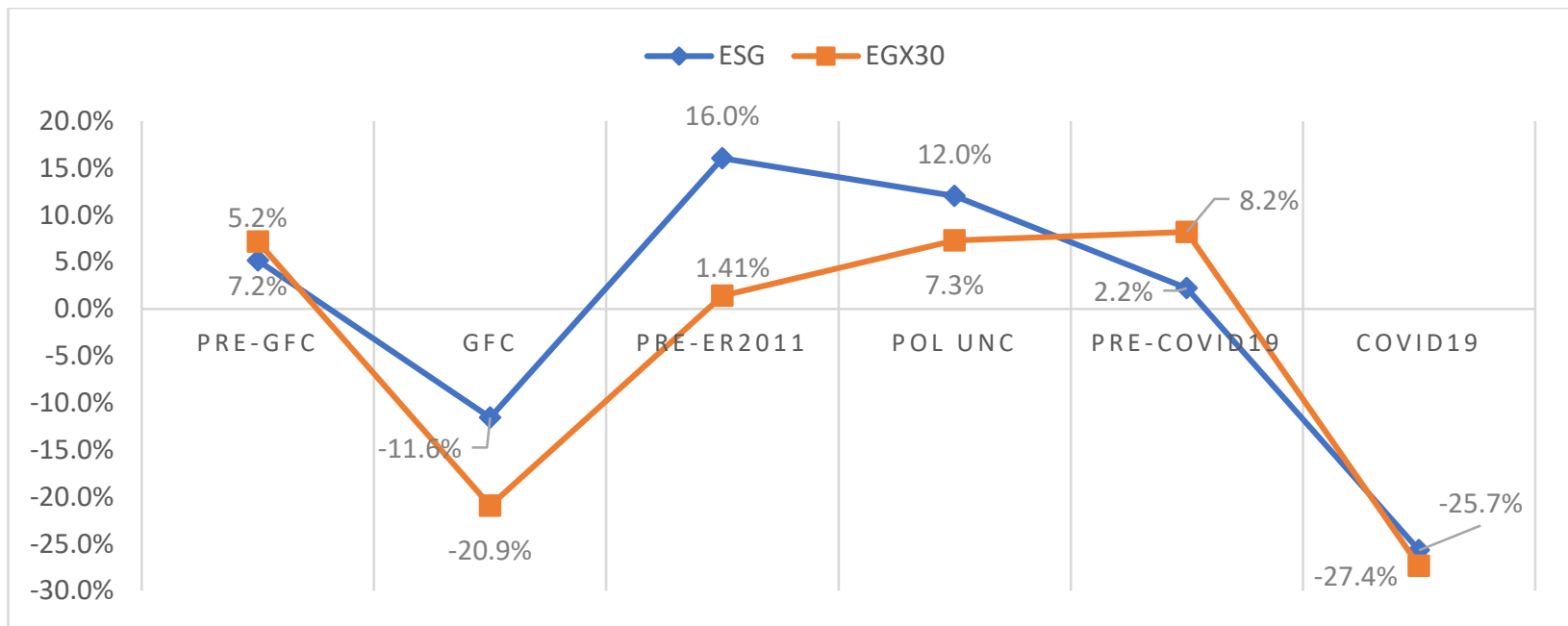

Figure 1: Annualized Returns of ESG and EGX30. Source: Depicted by the researcher based on data

12

العدد الأول - 2021 - 2021

مجلة الدراسات المالية والتجارية 
Beta coefficient of ESG index as a measure of its systematic (market) risk tend to be positive in all sub-periods, except in GFC period. However, small values of beta coefficient indicate less exposure of ESG index returns to market risks, but they result in large difference in values of Treynor ratio between ESG index and EGX30 index. Consistent with performance of annualized return in figure (1), values of sharp ratio for ESG index compared to that for EGX30 index during different periods are depicted in figure (2) indicate that ESG index provides higher (lower) excess return units per each unit of total risk than those provided by EGX30 index during four (two) subperiods. Jensen's Alpha coefficient of ESG index has negative values during all sub-periods, except during Pre-ER2011 it has positive value of 0.05. Those signs indicate that returns of ESG index underperforms market index during most periods and outperforms market index during normal conditions before uprising in 2011. It is observed that annualized excess return during all periods are negative for both indexes because of superiority of risk-free rates on 252 days-treasury bills (except in the Pre-ER2011 period). Consequently, most values of both sharp ratio and Treynor ratio would have negative values. Therefore, to simplify comparison, we use a straightforward measure of relative performance, reward-to-risk (RTR) measure, which adjusts total return (instead of the excess return than risk-free rate) of each index by its standard deviation.

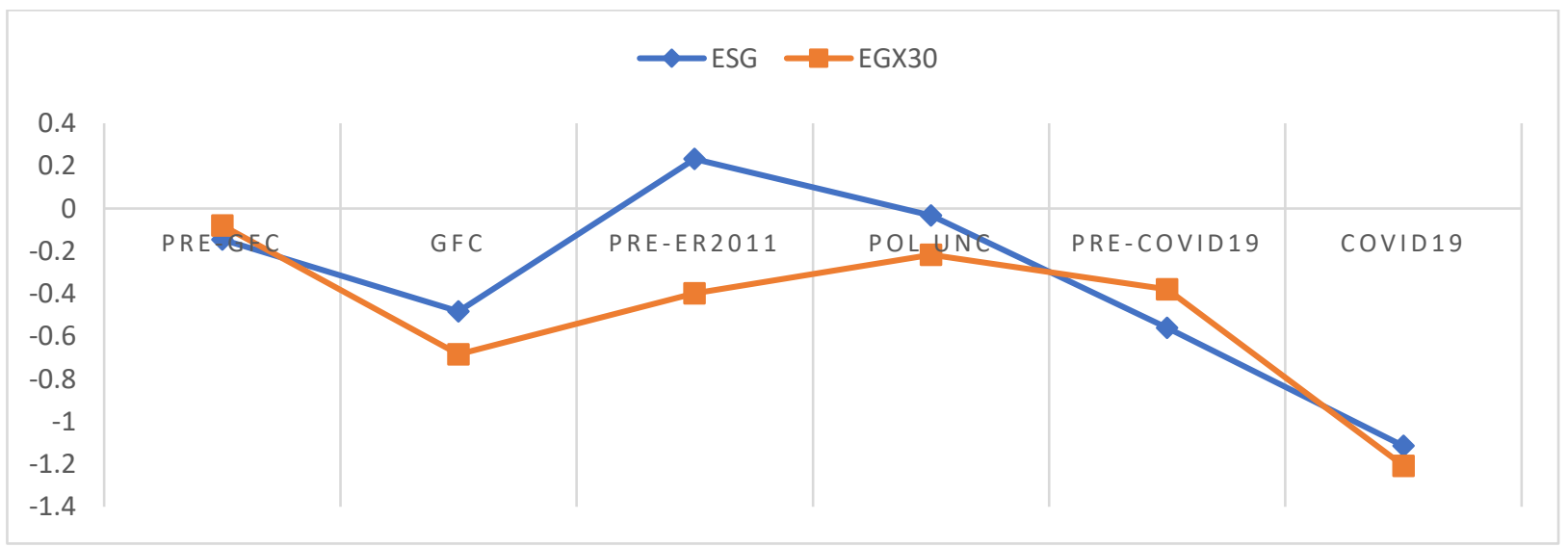

Figure 2: Sharp Ratio of ESG and EGX Indexes. Source: Depicted by the researcher based on data

13

العدد الأول - 2021

مجلة الدراسات المالية والتجارية 
Table 3 Risk-adjusted Return Performance Measures for ESG and EGX30 Indexes during Different Periods

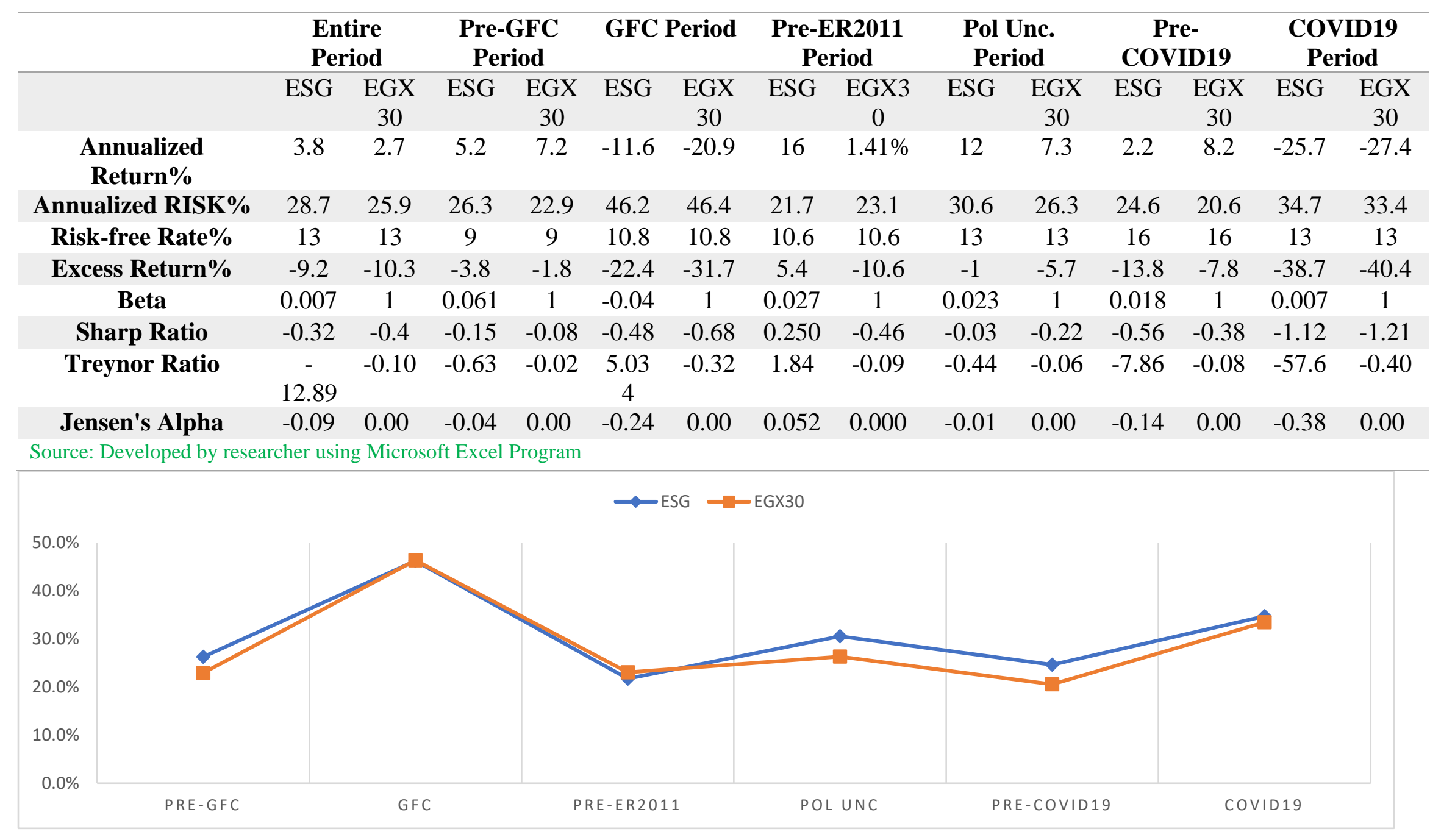

Figure 3: Annualized Standard Deviation of ESG and EGX30 Returns. Source: Depicted by the researcher based on data

$$
2021 \text { - العدد الأول }
$$




\subsection{Estimation of Conditional Volatility of Index Return Series}

A classical pre-test for time series analysis is unit root test while we need to conduct two pre-estimation tests: serial correlation and heteroscedasticity test to ensure suitability of GARCH model to our data. We discuss each test and its result in the following sections.

\subsubsection{Stationarity (Unit Root) Test}

Index series usually have a unit root - data has a systematic pattern - which could result in a spurious relationship. We perform augmented Dickey-Fuller (ADF) unit root test to examine null hypothesis that index daily values series has a unit root. Table (4) presents the ADF results for index values at level which could not reject the null hypothesis, indicating the non-stationarity of the index values series. Therefore, we need to take the first difference to generate return series which successfully remove unit root from the series. So, return series for both indexes are stationary and can be used in regression analysis.

Table 4 Results of augmented Dickey-Fuller unit root test on level series and return series of Index series

\begin{tabular}{|cccccc|}
\hline & & \multicolumn{2}{c}{ Level Series } & \multicolumn{2}{c|}{ Return Series } \\
\hline Index & $1 \%$ Critical & Test & $\mathrm{P}$ value for & Test & $\mathrm{P}$ value for \\
Series & Value & Statistic & $\mathrm{Z}(\mathrm{t})$ & Statistic & $\mathrm{Z}(\mathrm{t})$ \\
\hline ESG & -3.4322 & -1.2877 & 0.6375 & -37.0266 & 0.0000 \\
\hline EGX30 & -3.4322 & -1.2165 & 0.6695 & -45.9490 & 0.0001 \\
\hline
\end{tabular}

Source: Developed by the researcher Using Eviews10 Software Package.

\subsubsection{Serial Correlation Test}

We conduct Ljung-Box Q test to examine null hypothesis of no serial correlation in each index return series. Typically, we regress each return series on a constant and one-period lagged value of the index series of interest. As reported in appendix 1, results of Ljung-Box Q test reject the null hypothesis of autocorrelation up to 36 days at probability values less than $1 \%$ for ESG index but the results for EGX30 index return series appears mixed, so we apply a more powerful serial correlation test: Ljung-Box $\mathrm{Q}^{2}$ test which successfully reject the null hypothesis at significance level of $1 \%$ up to 36 lagged days, as reported in appendix 1. 


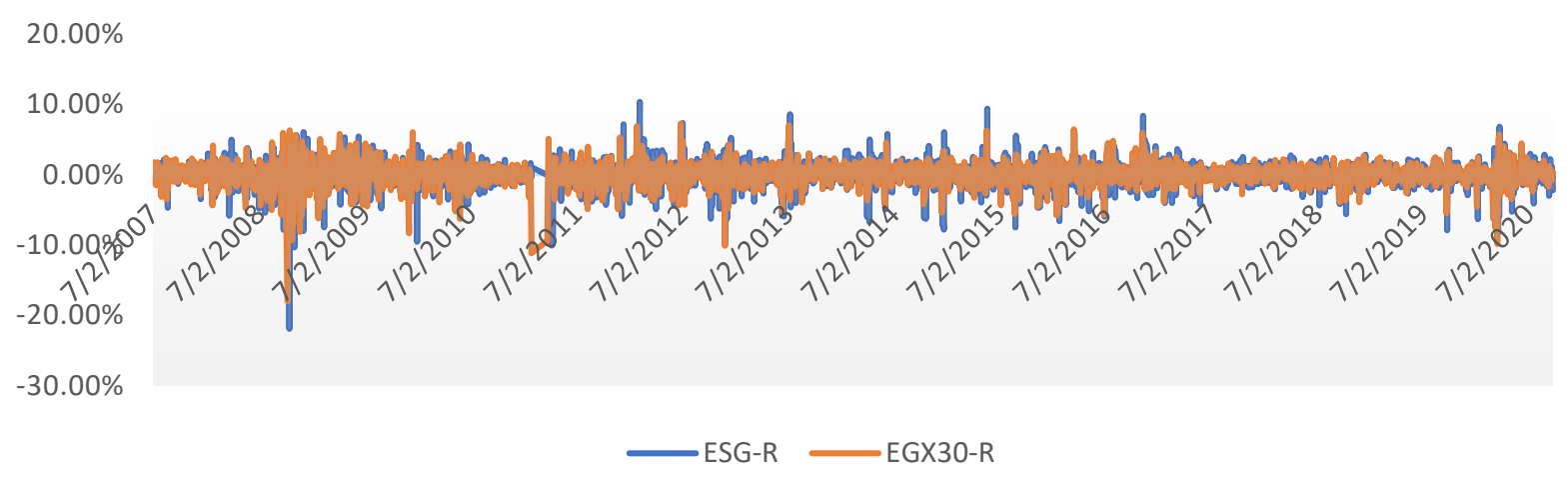

Figure 4: Trend line of return series of ESG and EGX30 Index. Source: Depicted by the researcher Based on data.

\subsubsection{Testing for "ARCH effects"}

Figure 4 displays the movement of the returns of ESG index along with the EGX30 index returns during the period 2007-2020 which reflects a time-varying volatility in returns of both indexes. To ensure empirically such observation, we apply a Lagrange multiplier test (ARCH-LM) of Engle (1982) to examine heteroscedasticity for each index return series. Typically, this test has a null hypothesis of no ARCH effects in the residuals. Rejecting the null hypothesis is a prerequisite for modeling volatility using GARCH models. We regress the squared residuals on a constant and 10 periods lagged values of each index return series. Appendix (1) show results of ARCH-LM test which reject the null hypothesis of no ARCH effects for both indexes return series at significant level of $1 \%$. Thus, the GARCH model is suitable for modeling volatility of the indexes returns.

Table 5 Results of ARCH-LM Test

\begin{tabular}{lcc}
\hline & ESG Index & EGX30 Index \\
\hline F-statistic (Prob.) & $11.31675(0.0000)$ & $24.53641(0.0000)$ \\
\hline Source: Developed by the researcher Using Eviews10 Software Package. &
\end{tabular}

\subsubsection{Results of TGARCH $(1,1)$ Model}

Table (6) shows results of TGARCH model for modeling volatility in returns of ESG and EGX30 indexes without and with including dummy variables for capturing impacts of GFC, POL and COVID19. Coefficients of ARCH $(\alpha)$, GARCH $(\beta)$ and asymmetric effect $(\eta)$ are positive and statistically significant at $1 \%$ level of significance. Measure of volatility persistence $(\alpha+\beta)$ are 0.9 and 0.88 for the ESG 
and EGX30 indexes, respectively. This indicates that volatility of ESG returns persists longer than that of EGX index returns. In contrast, coefficient of asymmetric effect $(\eta)$ for ESG index, 0.12, is lower than that for EGX30 index, 0.16, indicating that returns of EGX30 index (compared to ESG index returns) are more sensitive to negative return shocks than positive shocks of the same magnitude (leverage effect). Adding the dummy variables reduces slightly the volatility persistence, represented in measure of $\alpha+\beta$ for returns of both indexes while increases slightly values of asymmetric effect coefficient $(\eta)$.

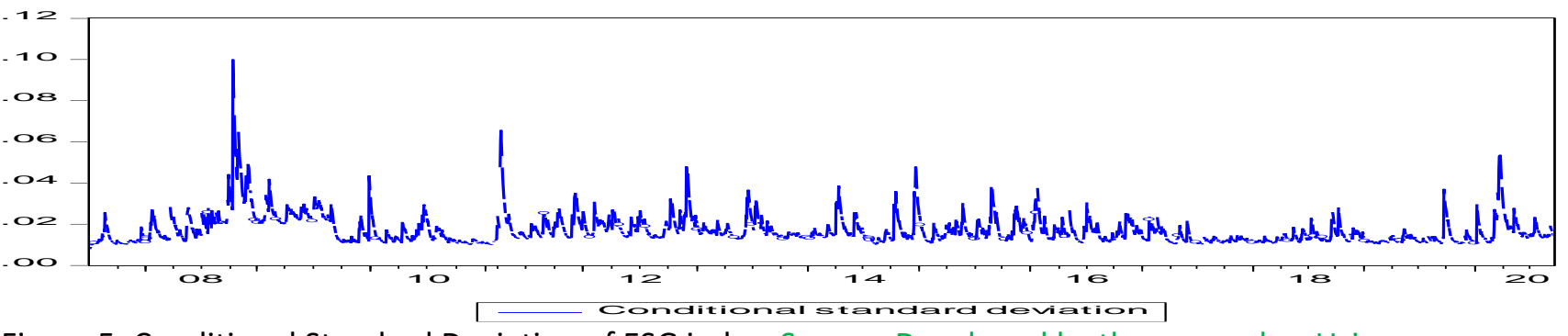

Figure 5: Conditional Standard Deviation of ESG index. Source: Developed by the researcher Using

Eviews10 Software Package.

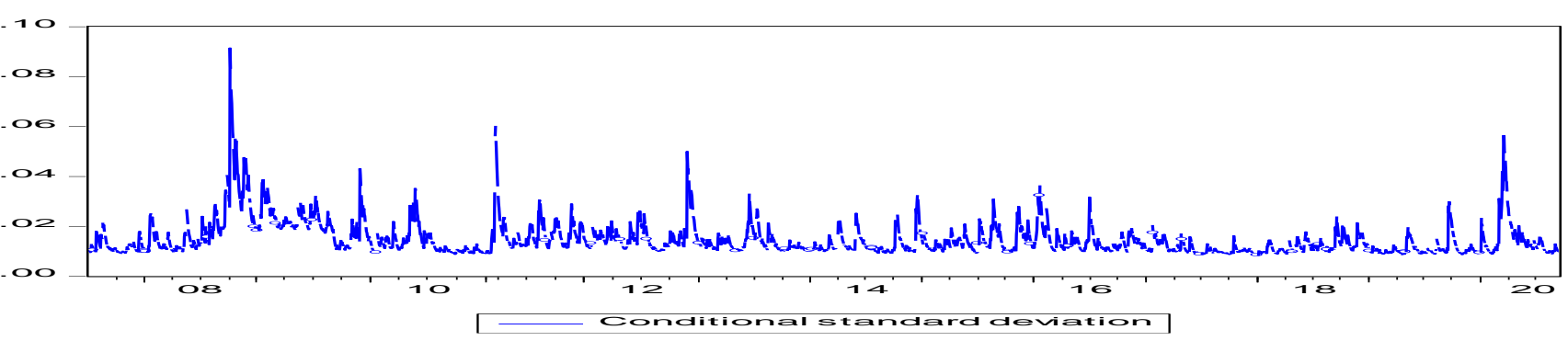

Figure 6: Conditional Standard Deviation of EGX30. Source: Developed by the researcher Using Eviews10 Software Package.

With respect of effect of exogenous shocks, dummy variables of GFC and POL are positive and statistically significant at $1 \%$ level but. During the global financial crisis (GFC) and political uncertainty periods, returns of ESG index are more volatile than those of EGX30 index. however, the magnitude of impact of both coefficients for both indexes are small. Interestingly, conditional volatility of both indexes reacts insignificantly to COVID19 pandemic. Figure 5 and 6 show conditional standard deviation performance of ESG index and EGX30 index, respectively. Obviously, there is no significant difference between trend line of volatility in returns of ESG and that of EGX index. This observation is supported by measure $\alpha+\eta / 2+\beta$ which has the same value of 0.96 for both indexes (without dummy variables) and small difference when we added dummy variables to equation of conditional variance. 
Table 6 Results of TGARCH $(1,1)$ model Estimation of ESG and EGX30 Index Series

\begin{tabular}{ccccccccc}
\hline Index Series & $\boldsymbol{\alpha}$ & $\boldsymbol{\eta}$ & $\boldsymbol{\beta}$ & GFC & POL & COVID-19 & $\boldsymbol{\alpha}+\boldsymbol{\beta}$ & $\boldsymbol{\alpha}+\boldsymbol{\eta} / \mathbf{2}+\boldsymbol{\beta}$ \\
\hline ESG & $0.08^{*}$ & $0.12^{*}$ & $0.82^{*}$ & & & & 0.90 & 0.96 \\
& $0.07^{*}$ & $0.13^{*}$ & $0.79^{*}$ & $0.00006^{*}$ & $0.00001^{*}$ & 0.00001 & 0.86 & 0.92 \\
EGX30 & $0.07^{*}$ & $0.16^{*}$ & $0.80^{*}$ & & & & 0.88 & 0.96 \\
& $0.06^{*}$ & $0.17^{*}$ & $0.78^{*}$ & $0.00004^{*}$ & $0.0000^{*}$ & 0.0000 & 0.84 & 0.93 \\
\hline
\end{tabular}

*indicates coefficient is significant at $1 \%$ level. Source: Developed by the researcher Using Eviews 10 Software Package.

\section{Discussion of Results}

On return level, the annualized returns of ESG index outperform those of market index during exogenous shocks periods: GFC, POL and COVID19 as well as during period prior to Egyptian revolution. This implies that investors could diversify their portfolios by holding high ESG ranked stocks to reduce negative effects of exogenous shocks. On corporate level, the companies should enhance their ESG practices and quality of reporting to maximize their market value and increase investors incentive to hold their stocks.

On risk level, Results of TGARCH model reveal that volatility of ESG index tends to be more persistent than that of EGX30 index but leverage effect of ESG volatility is lower than that of EGX30 index. During the global financial crisis and political uncertainty periods, returns of ESG index are more volatile than those of EGX30 index. Interestingly, conditional volatility of both indexes reacts insignificantly to COVID19 pandemic.

On risk-return trade-off level. Obviously, returns outperformance of ESG index during GFC, POL periods are associated with higher risk (measured by volatility of returns). Thus, risk-averse investors could assign lower percentage of portfolio to high-ESG ranked stocks to minimize portfolio volatility level. Conversely, the risklover investors could follow ESG investing strategies to maximize their portfolio returns.

\section{Conclusion and Recommendations}

The main objective of current paper is to examine risk-return characteristics of Environmental, Social and Governance (ESG) index of Egypt compared with a benchmark market index, EGX30 index using daily data over the period of 2007 to 2020. This period of consideration experience three major exogenous shocks that 
could have considerable effects on both return and risk of stock market. So, this paper seeks to capture effect of these shocks on risk-adjusted return as well as conditional volatility of ESG index and EGX30 index.

We employ common measures of risk-adjusted return in portfolio analysis including Sharp ratio, Treynor ratio and Jensen's alpha. Moreover, for modeling volatility of both indexes series, we use TGARCH model to estimate asymmetric effect negative return shocks have greater effect on volatility than positive return shocks of the same magnitude, in addition to measure volatility persistence of the ESG index compared to the EGX30 index.

The findings indicate that there is no significant difference in daily returns of ESG index and EGX30 index but annualized return of ESG index do better than that of EGX30 index (benchmark market). More specifically, the annualized returns of ESG index outperform those of market index during exogenous shocks periods: GFC, POL and COVID19 as well as during period prior to Egyptian revolution.

Results of TGARCH model reveal that volatility of ESG index tends to be more persistent than that of EGX30 index but leverage effect of ESG volatility is lower than that of EGX30 index. During the global financial crisis and political uncertainty periods, returns of ESG index are more volatile than those of EGX30 index. Interestingly, conditional volatility of both indexes reacts insignificantly to COVID19 pandemic.

This paper has important implications for companies listed in Egyptian exchange and investors. Firms should improve their ESG practices and reporting to enhance their market value in the market and increase investors incentive to hold their stocks. On the other hand, investors should follow ESG investing strategies to diversify their portfolios and to encourage firms to adopt more ESG plans which eventually results in targeted sustainable development.

The superiority of EGS returns over the market index in Egypt in most sub-periods indicates that ESG practices are well priced in the Egyptian stock market. Thus, further future empirical research is needed to examine capability of ESG factor in explaining cross-sectional returns using Egyptian data. 


\section{References:}

Abo-Elala, M. A. (2018). The Impact of Existing of Companies' in The Egyptian Corporate Responsibility Index ESG on The Accounting Conservatism: An Applied Study On companies existed in The index. Accounting Thought At Ain-Shams University (ATASU), 22(7), 463-519.

Aboud, A., \& Diab, A. (2018). The impact of social,environmental and corporate governance disclosureson firm value: Evidence from Egypt. Journal of Accounting in Emerging Economies, 8(4), 442-458.

Aboud, A., \& Diab, A. (2019). The financial and market consequences of environmental,social and governance ratings The implications of recent political volatility in Egypt. Sustainability Accounting, Management and Policy Journal, 2040-8021. doi:10.1108/SAMPJ-06-2018-0167

Arefeen, S., \& Shimada, K. (2020). Performance and Resilience of Socially Responsible Investing (SRI) and Conventional Funds during Di. Sustainability, 12(2), 1-20.

CFAInstitute. (2015). ENVIRONMENTAL, SOCIAL, AND GOVERNANCE ISSUES IN INVESTING: A Guide for Investment Professionals. CFA Institute.

CORTEZ, M. C., SILVA, F., \& AREAL, a. N. (2011). SOCIALLY RESPONSIBLE INVESTING IN THE GLOBAL MARKET: THE PERFORMANCE OF US AND EUROPEAN FUNDS. International Journal of Finance \& Economics, 1-18.

Curto, J. D., \& Vital, C. (2014). Socially Responsible Investment: A Comparison between the Performance of Sustainable and Traditional Stock Indexes. Journal of Reviews on Global Economics, 3, 349-363.

El-Mahdy, A. A. (2019). The Impact of Corporate Governance on Financing Decision of Listed Firms in S\&P EGX/ESG Index. Cairo: Ain Shams.

Engle, R. (1982). Autoregressive conditional heteroscedasticity with estimates of the variance of United Kingdom inflation. Econmetrica, 50(4), 987-1007. 
Jensen, M. C. (1968). The performance of mutual funds in the period 1945-1964. Journal of Finance, 23(2), 389-416.

Kempf, A., \& Osthoff, P. (2007). The Effect of Socially Responsible Investing on Portfolio Performance. European Financial Management, 13(5), 908-922.

Managia, Okimoto, T., \& Matsuda, A. (2012). Do socially responsible investment indexes outperform conventional indexes? Applied Financial Economics, 22, $1511-1527$.

Ortas, E., Moneva, J. M., \& Salvador, M. (2010). Conditional volatility in sustainable and traditional stock exchange indexes: analysis of the Spanish market. Revista Journal, 4(2), 104-129.

Rehman, R. U., Zhang, J., Uppal, J., Cullinan, C., \& Naseem, M. A. (2016). Are environmental social governance equity indices a better choice for investors? An Asian perspective. Business Ethics: A European Review, 25(4), 440-459.

S\&PDowJones. (2020, Sep. 27). S\&P Methodology for S\&P/EGX ESG Index. Retrieved from The Egyptian Exchange: https://www.egx.com.eg/en/indexrulesmethodologys-p-egx.aspx?nav=7

Schröder, M. (2004). THE PERFORMANCE OF SOCIALLY RESPONSIBLE INVESTMENTS: INVESTMENT FUNDS AND INDICES. FINANCIAL MARKETS AND PORTFOLIO MANAGEMENT, 18(2), 122-142.

Schroder, M. (2007). Is there a Difference? The Performance Characteristics of SRI Equity Indices. Journal of Business Finance \& Accounting, 34(1 \& 2), 331-348.

Sharpe, W. (1966). Mutual fund performance. Journal of Business, 39(1), 119138.

Sudha, S. (2014). Risk-return and Volatility analysis of Sustainability Index in India. Environment Development and Sustainability, 16(6). doi:10.1007/s10668-014-9608-8

Tripathi, V., \& Kaur, A. (2020). Socially Responsible Investing: Performance Evaluation of BRICS Nations. Journal of Advances in Management Research, 17(4), 525-547. doi:10.1108/JAMR-02-2020-0020 


\section{Appendices}

Appendix 1 Results of Serial Correlation Tests for ESG and EGX30 Indices

\begin{tabular}{|c|c|c|c|c|c|c|c|c|}
\hline $\begin{array}{l}\text { \# of } \\
\text { Lags }\end{array}$ & \multicolumn{6}{|l}{ Ljung-Box Q Test for ESG Index } & \multicolumn{4}{|c|}{ Ljung-Box Q ${ }^{2}$ Test for EGX30 } \\
\cline { 2 - 10 } & AC & PAC & Q-Stat & Prob & AC & PAC & Q-Stat & Prob \\
\hline 1 & 0.00 & 0.00 & 0.02 & 0.90 & 0.16 & 0.16 & 82.66 & 0.00 \\
\hline 2 & 0.06 & 0.06 & 10.69 & 0.01 & 0.14 & 0.12 & 143.76 & 0.00 \\
\hline 3 & 0.03 & 0.03 & 13.94 & 0.00 & 0.13 & 0.09 & 193.84 & 0.00 \\
\hline 4 & 0.03 & 0.02 & 15.90 & 0.00 & 0.14 & 0.10 & 260.22 & 0.00 \\
\hline 5 & 0.02 & 0.02 & 17.56 & 0.00 & 0.12 & 0.06 & 303.10 & 0.00 \\
\hline 6 & -0.01 & -0.01 & 17.63 & 0.01 & 0.09 & 0.03 & 326.54 & 0.00 \\
\hline 7 & -0.02 & -0.02 & 18.33 & 0.01 & 0.14 & 0.10 & 392.16 & 0.00 \\
\hline 8 & 0.01 & 0.01 & 18.75 & 0.02 & 0.09 & 0.02 & 416.51 & 0.00 \\
\hline 9 & 0.00 & 0.00 & 18.77 & 0.03 & 0.10 & 0.04 & 446.34 & 0.00 \\
\hline 10 & 0.02 & 0.02 & 20.13 & 0.03 & 0.06 & 0.00 & 457.10 & 0.00 \\
\hline 11 & 0.05 & 0.05 & 28.22 & 0.00 & 0.18 & 0.13 & 559.42 & 0.00 \\
\hline 12 & 0.03 & 0.03 & 31.37 & 0.00 & 0.05 & -0.03 & 568.28 & 0.00 \\
\hline 13 & 0.02 & 0.01 & 32.11 & 0.00 & 0.10 & 0.04 & 598.15 & 0.00 \\
\hline 14 & -0.02 & -0.03 & 33.41 & 0.00 & 0.04 & -0.03 & 602.07 & 0.00 \\
\hline 15 & -0.01 & -0.02 & 33.87 & 0.00 & 0.07 & 0.02 & 617.29 & 0.00 \\
\hline 16 & -0.01 & -0.01 & 34.02 & 0.01 & 0.03 & -0.03 & 619.52 & 0.00 \\
\hline 17 & -0.01 & -0.01 & 34.25 & 0.01 & 0.06 & 0.03 & 630.90 & 0.00 \\
\hline 18 & 0.01 & 0.01 & 34.52 & 0.01 & 0.09 & 0.04 & 655.75 & 0.00 \\
\hline 19 & 0.03 & 0.03 & 37.48 & 0.01 & 0.05 & 0.01 & 662.80 & 0.00 \\
\hline 20 & 0.01 & 0.01 & 37.88 & 0.01 & 0.05 & -0.01 & 669.55 & 0.00 \\
\hline 21 & 0.00 & -0.01 & 37.90 & 0.01 & 0.03 & 0.00 & 672.12 & 0.00 \\
\hline 22 & 0.04 & 0.03 & 41.89 & 0.01 & 0.03 & -0.02 & 675.73 & 0.00 \\
\hline 23 & 0.01 & 0.01 & 42.29 & 0.01 & 0.02 & 0.01 & 677.60 & 0.00 \\
\hline 24 & 0.00 & -0.01 & 42.35 & 0.01 & 0.04 & 0.01 & 683.75 & 0.00 \\
\hline 25 & -0.01 & -0.01 & 42.49 & 0.02 & 0.03 & 0.01 & 686.71 & 0.00 \\
\hline 26 & 0.00 & 0.00 & 42.50 & 0.02 & 0.06 & 0.03 & 698.56 & 0.00 \\
\hline 27 & -0.02 & -0.02 & 44.42 & 0.02 & 0.04 & 0.02 & 703.64 & 0.00 \\
\hline 28 & -0.02 & -0.02 & 45.23 & 0.02 & 0.03 & -0.01 & 705.89 & 0.00 \\
\hline 29 & -0.01 & -0.01 & 45.63 & 0.03 & 0.04 & 0.01 & 711.94 & 0.00 \\
\hline 30 & 0.01 & 0.01 & 45.77 & 0.03 & 0.10 & 0.07 & 742.90 & 0.00 \\
\hline 31 & 0.02 & 0.02 & 46.61 & 0.04 & 0.01 & -0.04 & 743.17 & 0.00 \\
\hline & & & & & & & & \\
\hline
\end{tabular}




\begin{tabular}{|l|c|c|c|c|c|c|c|c|}
\hline 32 & -0.01 & -0.01 & 47.29 & 0.04 & 0.04 & 0.02 & 748.40 & 0.00 \\
\hline 33 & -0.03 & -0.03 & 50.24 & 0.03 & 0.06 & 0.03 & 760.55 & 0.00 \\
\hline 34 & 0.02 & 0.02 & 52.11 & 0.02 & 0.08 & 0.05 & 783.39 & 0.00 \\
\hline 35 & 0.00 & 0.00 & 52.13 & 0.03 & 0.08 & 0.03 & 801.49 & 0.00 \\
\hline 36 & 0.01 & 0.01 & 52.26 & 0.04 & 0.02 & -0.03 & 802.22 & 0.00 \\
\hline
\end{tabular}

